\title{
DESIGN OF HEXAGONAL FRACTAL ANTENNA FOR WLAN/ WiMAX \& BLUETOOTH APPLICATIONS
}

\author{
Deepshikha Yadav', DC Dhubkarya ${ }^{2}$ \\ ${ }^{1}$ Bundelkhand Institute of Engineering and Technology, Jhansi, U.P. India \\ ${ }^{2}$ Bundelkhand Institute of Engineering and Technology, Jhansi, U.P. India
}

\begin{abstract}
In this paper, hexagonal fractal antenna is investigated for wide band applications. The proposed antenna is made by removing the equilateral triangles of required dimensions. Modified line feed is used for designing the antenna to achieve wide bandwidth ranging from $1.751 \mathrm{Ghz}$ to $2.856 \mathrm{Ghz}$ with a bandwidth $47.97 \%$.In the present work size reduction has been achieved. It offers gain of 2.88dBi, directivity of $3.12 \mathrm{dBi}$ and antenna efficiency of $94.57 \%$ at $1.95 \mathrm{Ghz}$ resonant frequency. This antenna is suitable for WLAN, WiMAX and Bluetooth applications. The proposed antenna is simulated by IE3D Zeland simulation software based on method of moments.
\end{abstract}

Keywords: microstrip antenna, fractal, hexagonal bandwidth, line feed, WLAN, IE3D, miniaturization.

\section{INTRODUCTION}

In todays era, requirement of antennas demand high performance, high gain, wide bandwidth, multiband support, low cost and minituraziation. Microstrip antennas possess these advantages along with compatibility with monolithic microwave integrated circuits(MMICs) [1-3]. Microstrip antenna possess disadvantages as well like narrow bandwidth and lower gain. There are many approaches to reduce the size of the antenna and increase the bandwidth without much affecting the antenna performance. One of these techniques is fractal antenna.

The origin of word 'fractal' is from the Latin word fractus which is related to the verb fangere means to break [4-5]. Fractal antenna uses self similar structure to maximize the length or increase the perimeter on inside sections or the outer structure of the material that can receive or transmit electromagnetic radiations within a given total surface area or volume[6]. Certain fractals represent multiband behavior and space-filling properties as reduction in antenna size[711]. In the present work, the bandwidth of microstrip antenna is enhanced to $47.97 \%$. The fourth iterated antenna is shown in Figure 1.The frequency band of this antenna is between $1.751 \mathrm{Ghz}$ to $2.856 \mathrm{Ghz}$ which is suitable for WLAN, WiMAX and Bluetooth applications[9-12]. This antenna has been designed on glass epoxy substrate $\left(\varepsilon_{\mathrm{r}}=4.4\right)$ [13].The substrate material has large effect in determining the size and bandwidth of an antenna. If the dielectric constant is increased, size of the antenna decreases but it lowers the bandwidth and efficiency of the antenna. If dielectric constant is decreased, bandwidth increases with an increase in size.

\section{ANTENNA DESIGN SPECIFICATIONS}

The design of fourth iterated antenna is shown in figure1. The antenna is designed by using glass epoxy substrate having the dielectric constant 4.4. The ground plane length and width are taken as $44 \mathrm{~mm}$ and $45 \mathrm{~mm}$ respectively. A regular hexagon of side $16 \mathrm{~mm}$ is taken and six equilateral triangles of side $8 \mathrm{~mm}$ are taken out so that we obtain first iteration. Then from first iterated antenna, six equilateral triangles of side $4 \mathrm{~mm}$ are taken out so that we obtain second iterated antenna. Then again six equilateral triangles of side $2 \mathrm{~mm}$ are taken so that we obtain third iterated antenna. Then again six equilateral triangles of side $1 \mathrm{~mm}$ are taken out so that we obtain fourth iterated antenna. Height of the dielectric substrate is $1.6 \mathrm{~mm}$ and loss tangent $\tan \delta$ is 0.0013 .Microstrip line feed is applied. Antenna is fed through $0.3 \mathrm{~mm}$ probe. Simulation work is done by using IE3D simulation software. All the specifications are given in table 1 (all lengths in $\mathrm{mm}$ and frequency in $\mathrm{GHz}$ ).

\section{ANTENNA DESIGN PROCEDURE}

The primary hexagonal shaped patch is having side length of $16 \mathrm{~mm}$.From that patch, six equilateral triangles of side length ' $a$ ' $8 \mathrm{~mm}$ has been taken out to obtain first iteration. Then six equilateral triangles of side length ' $b$ ' $4 \mathrm{~mm}$ has been taken out which results in second iteration. Then again six equilateral triangles of side 'c' $2 \mathrm{~mm}$ are taken out to obtain third iteration. Then again six equilateral triangles of side 'd' $1 \mathrm{~mm}$ are taken out to obtain fourth iteration. Figure 2 shows the design procedure of the proposed Fractal structure geometry, depicting $0^{\text {th }}$ iteration, $1^{\text {st }}$ iteration, $2^{\text {nd }}$ iteration, $3^{\text {rd }}$ iteration and $4^{\text {th }}$ iteration. The proposed antenna can also be called as hexagonal fractal antenna, as it is obtained after four iterations of structure. Line feed is used. The probe feed is placed at point $(\mathrm{X}=21.8125, \mathrm{Y}=2.5)$. During the designing of proposed antenna on IE3D ground plane is starting from $(0,0)$ at lower left corner. The geometry of proposed antenna is shown in figure1.A slot of size $(10 \times 10 \mathrm{~mm})$ is introduced in order to enhance the bandwidth. 


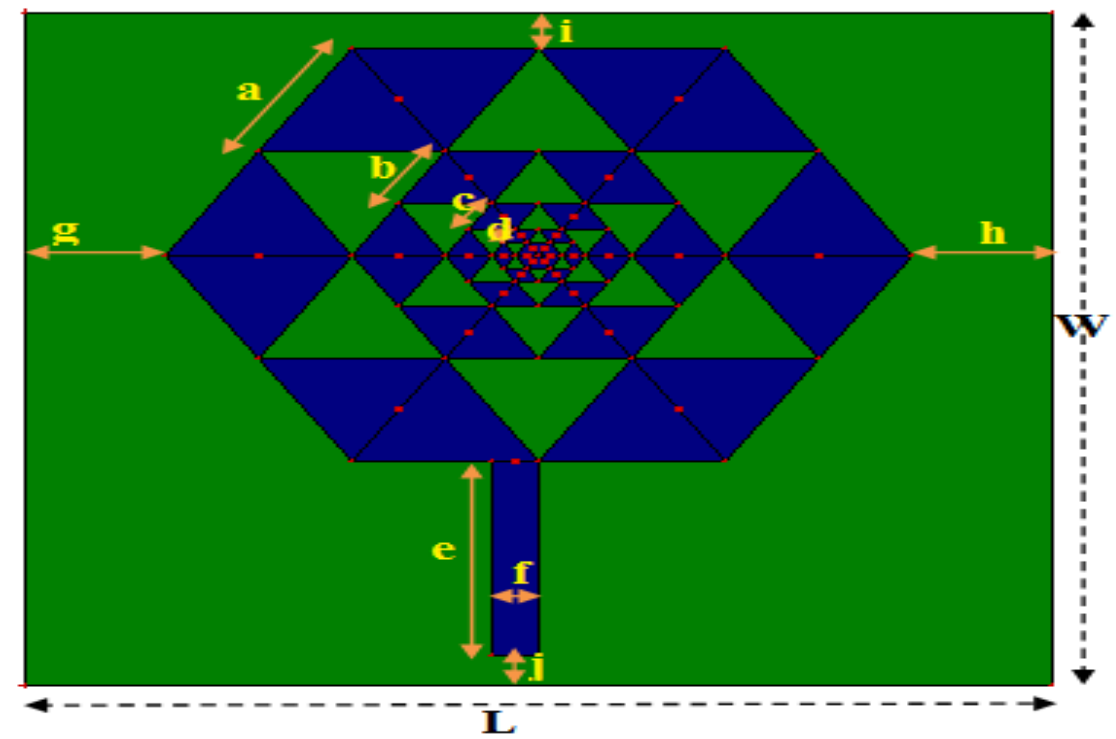

Fig.1. Geometry of proposed Microstrip antenna

Table1: Antenna design specifications

\begin{tabular}{|l|l|l|}
\hline S.No. & Parameters & Values \\
\hline 1. & dielectric constant $\varepsilon_{\mathrm{r}}$ & 4.4 \\
\hline 2. & Substrate height & $1.6 \mathrm{~mm}$ \\
\hline 3. & Ground plane width, $\mathrm{W}$ & $45 \mathrm{~mm}$ \\
\hline 4. & Ground plane length, $\mathrm{L}$ & $44 \mathrm{~mm}$ \\
\hline 5. & a & $8 \mathrm{~mm}$ \\
\hline 6. & b & $4 \mathrm{~mm}$ \\
\hline 7. & c & $2 \mathrm{~mm}$ \\
\hline 8. & d & $1 \mathrm{~mm}$ \\
\hline 9. & e & $13 \mathrm{~mm}$ \\
\hline 10. & f & $2 \mathrm{~mm}$ \\
\hline 11. & $\mathrm{~g}$ & $6 \mathrm{~mm}$ \\
\hline 12. & h & $6 \mathrm{~mm}$ \\
\hline 13. & i & $2.32 \mathrm{~mm}$ \\
\hline 14. & $\mathrm{j}$ & $2 \mathrm{~mm}$ \\
\hline
\end{tabular}

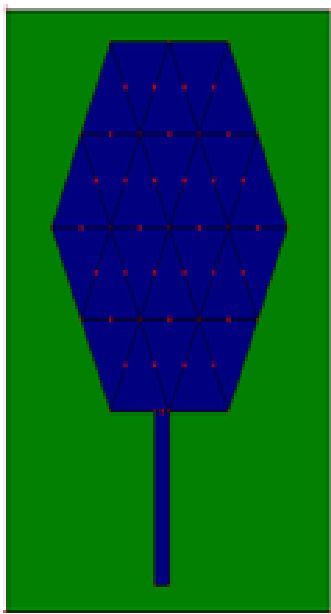

$0^{\text {th }}$ iteration

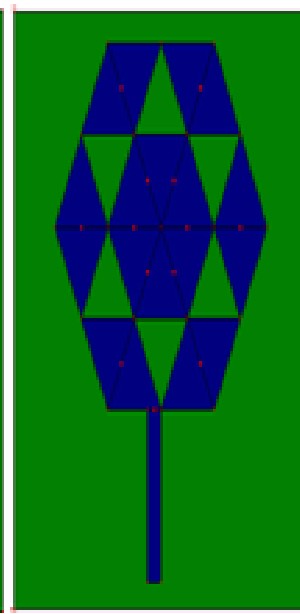

$1^{\text {st }}$ iteration

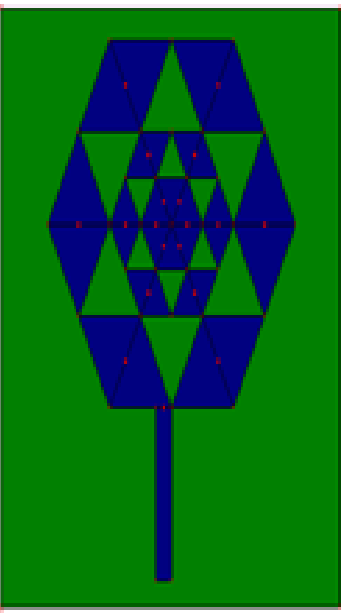

$2^{\text {nd }}$ iteration

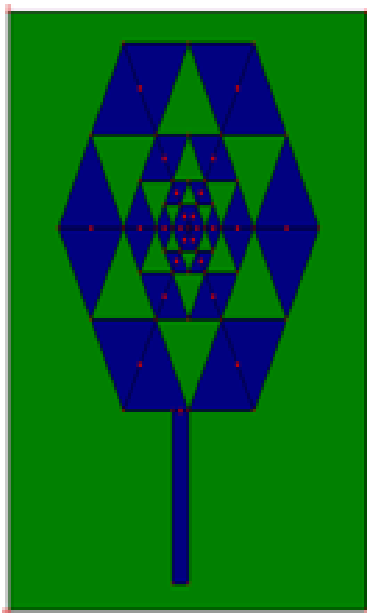

$3^{\text {rd }}$ iteration

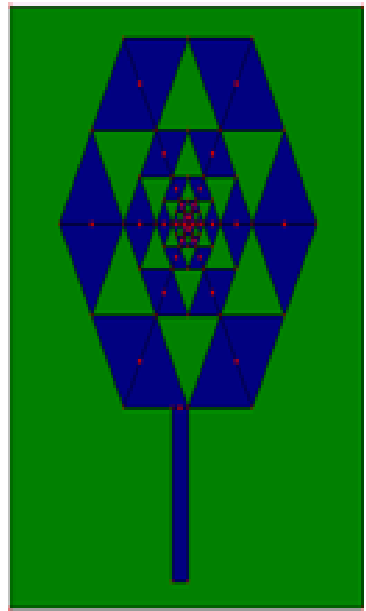

$4^{\text {th }}$ iteration

Fig 2 Various iterations of hexagonal-shaped fractal antenna 


\section{SIMULATION RESULT AND DISCUSSION}

The simulated return losses of $0^{\text {th }}$ iteration, $1^{\text {st }}$ iteration $2^{\text {nd }}$ iteration, $3^{\text {rd }}$ iteration and $4^{\text {th }}$ iteration are shown in figure 3 . It is clearly observed that size reduction has been achieved in $1^{\text {st }}, 2^{\text {nd }}, 3^{\text {rd }}$ and $4^{\text {th }}$ iteration. It is due to the fact that as the order of iteration increases, electrical path length increases which leads to the lowering of resonance frequency. Thus, this property can be utilized for size reduction.

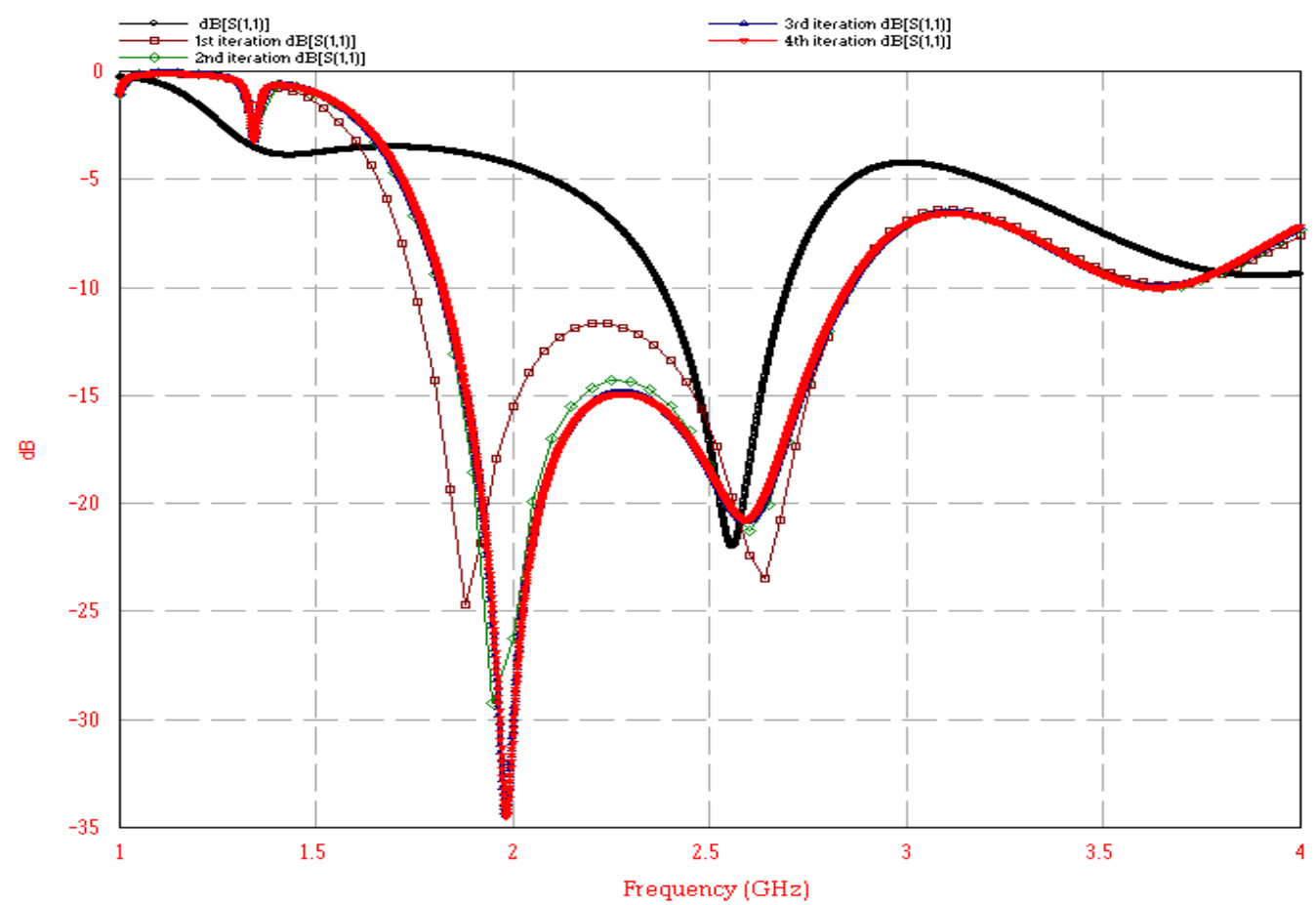

Fig.3. Return loss graph for $0^{\text {th }}, 1^{\text {st }}, 2^{\text {nd }}, 3^{\text {rd }} \& 4^{\text {th }}$ iteration

Table 2, summarizes the simulated results of zeroth, first, second, third and fourth iterated antenna. The first iterated antenna is the proposed antenna which shows quiet a good return loss, bandwidth, VSWR and size reduction.

The fractional bandwidth of proposed antenna is $47.97 \%$. The efficiency of proposed antenna is found to be $94.56 \%$.The gain of antenna is $2.88 \mathrm{dBi}$ and the directivity is found to be $3.12 \mathrm{dBi}$. VSWR of the antenna is in between 1 to 2 over the entire frequency band.

Table 2: Comparison of various parameters of different iterations

\begin{tabular}{|c|c|c|c|c|c|c|}
\hline ITERATION & BANDWIDTH & $\begin{array}{l}\text { RETURN } \\
\text { LOSS }\end{array}$ & GAIN & DIRECTVITY & $\begin{array}{l}\text { ANTENA } \\
\text { EFFCLENCY }\end{array}$ & AREA \\
\hline & $(\%)$ & $(d B)$ & $(\mathrm{dB} B)$ & $(d B i)$ & $|\%|$ & $\left(\mathrm{mm}^{2} \mid\right.$ \\
\hline $0^{\text {th }}$ & 12.64 & 23,94 & 2.62 & 3.2 & 87,58 & 665.04 \\
\hline $1^{t t}$ & 47,97 & $.33,03$ & 2.88 & 3.12 & 94.56 & 498.78 \\
\hline $2^{n d}$ & 44.87 & .33 .43 & 2.87 & 3.07 & 95,64 & 457,26 \\
\hline $3^{d 0}$ & 44.28 & $.34,49$ & 2.86 & 3.05 & 95,62 & 466.82 \\
\hline $4^{\text {th }}$ & 44.23 & $-34,41$ & 2.86 & 3.06 & 95,61 & 444,18 \\
\hline
\end{tabular}

The simulation performance of proposed microstrip patch antenna is analyzed by using IE3D version 9.0software.The performance specifications like radiation pattern etc of proposed antenna is shown in the figures 4 to 8 . Figure 9(a),(b) shows the front and back view of the fabricated antenna.

- $\mathbf{f}=\mathbf{1 . 9 6}(\mathrm{GHz}), \mathrm{E}$-total, phi $=0$ (deg) f=1.96 $(\mathrm{GHz})$, E-total, phi $=90(\mathrm{deg})$

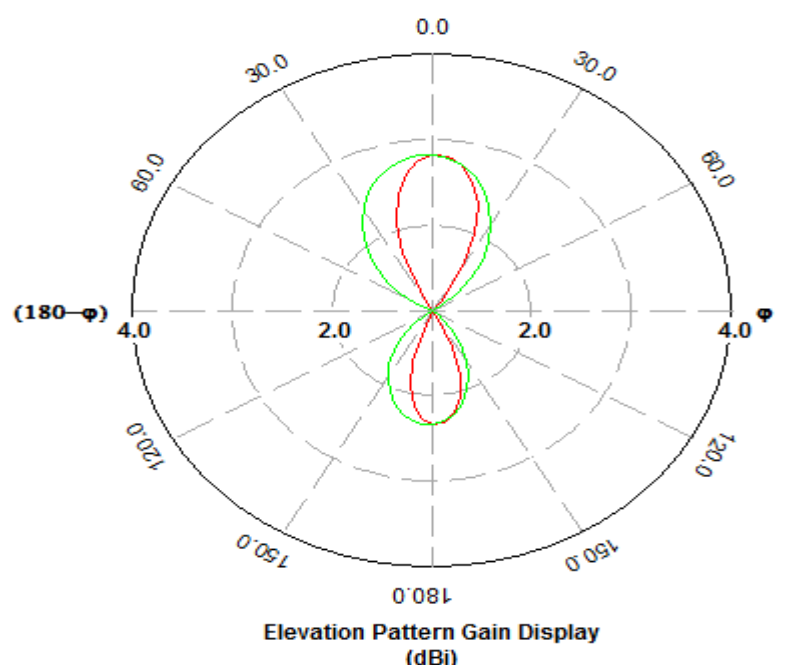

Fig.4. 2D Radiation pattern of proposed antenna 


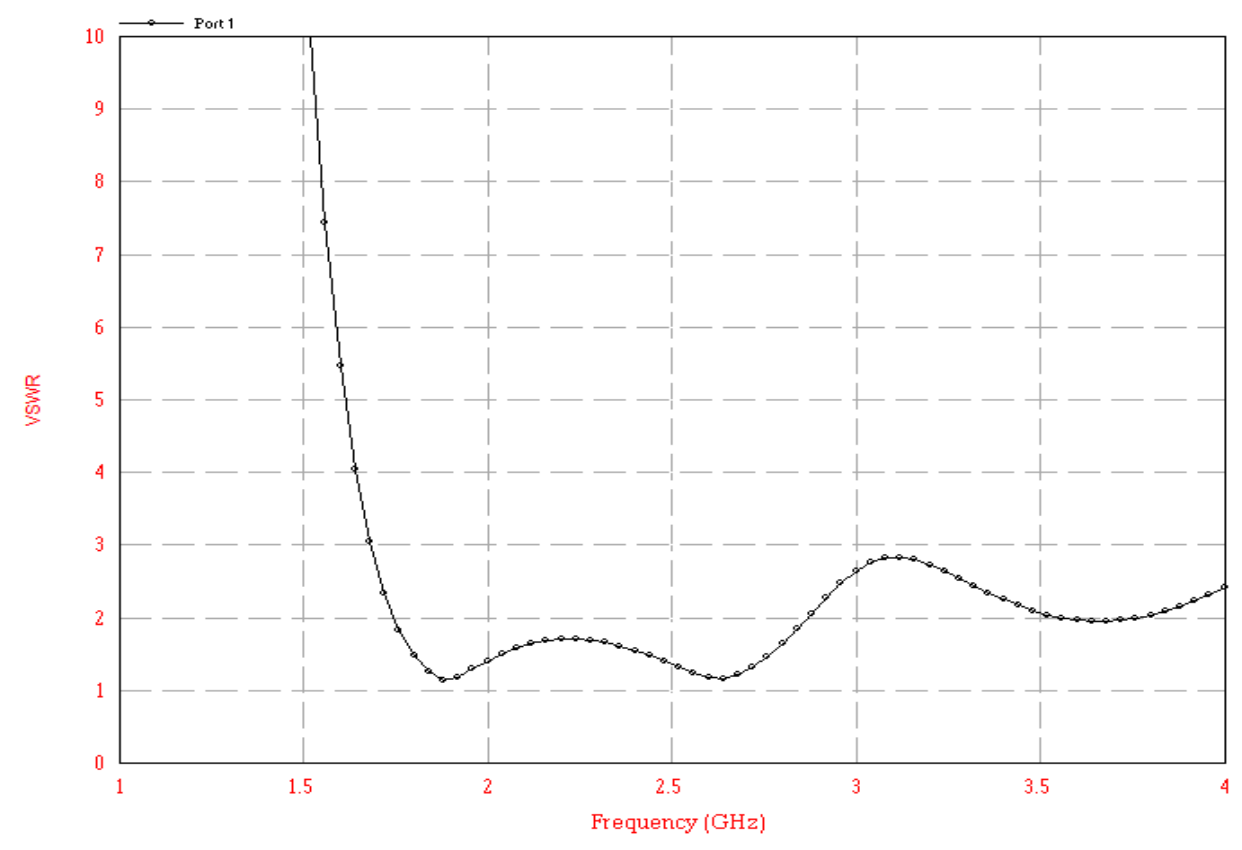

Fig 5 VSWR of proposed antenna

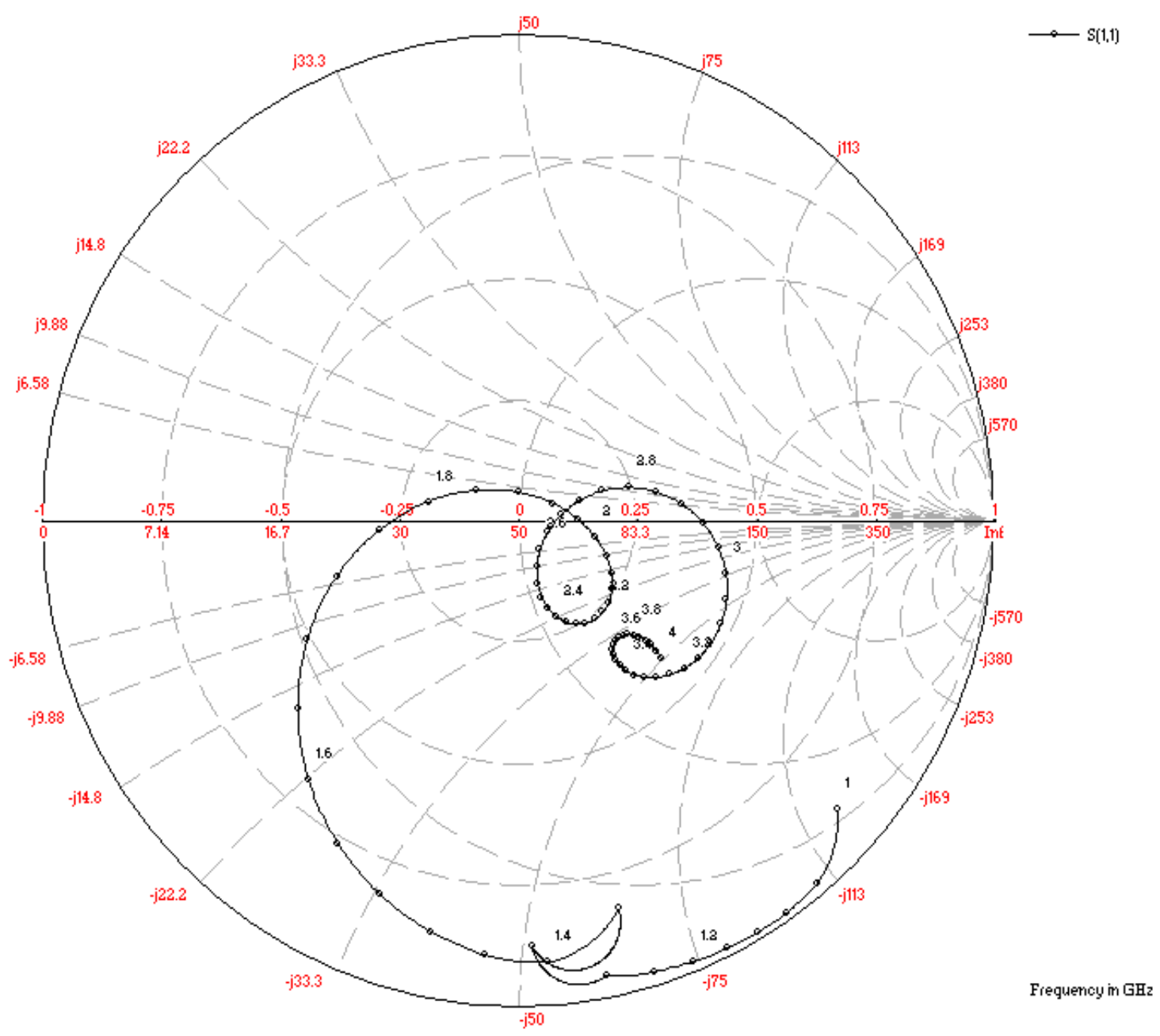

Fig 6 Smith chart of proposed antenna 


\section{Directivity Vs. Frequency}

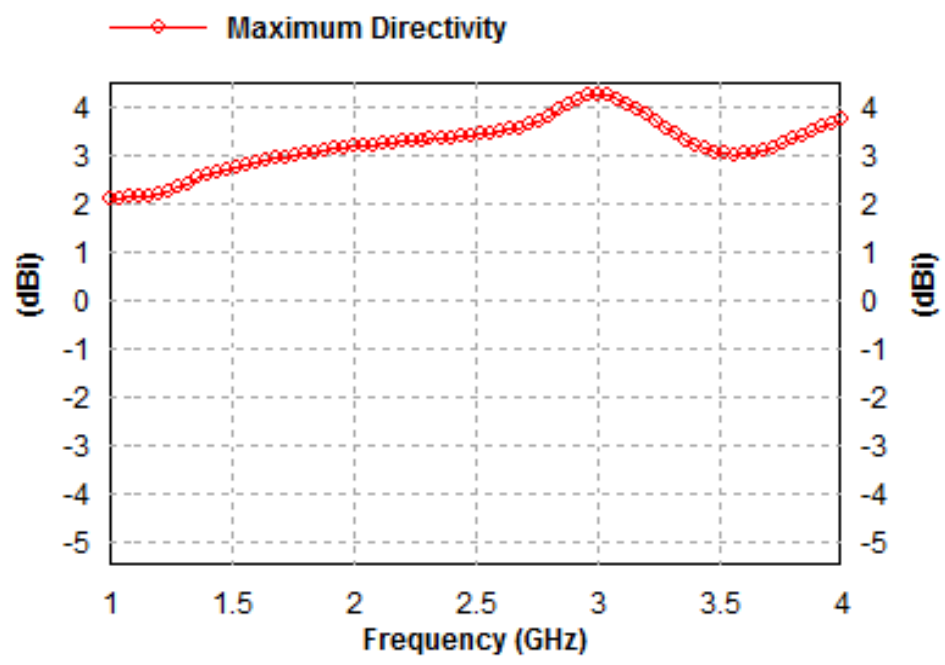

Fig 7 Directivity of proposed antenna

\section{Gain Vs. Frequency}

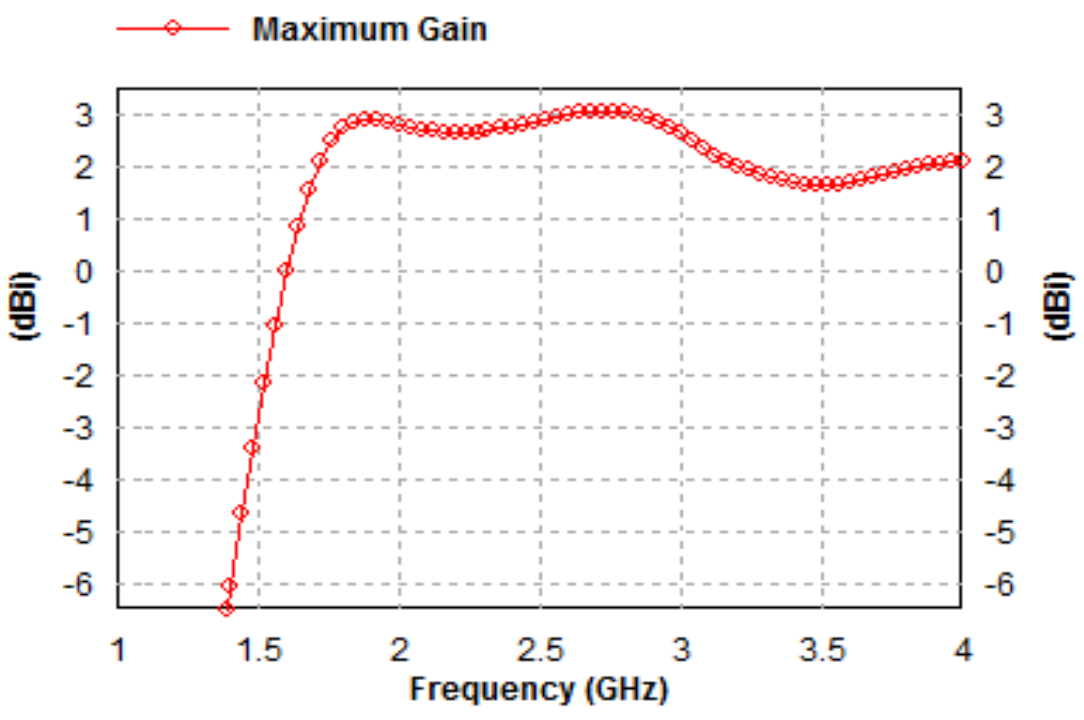

Fig.8. Gain of proposed antenna

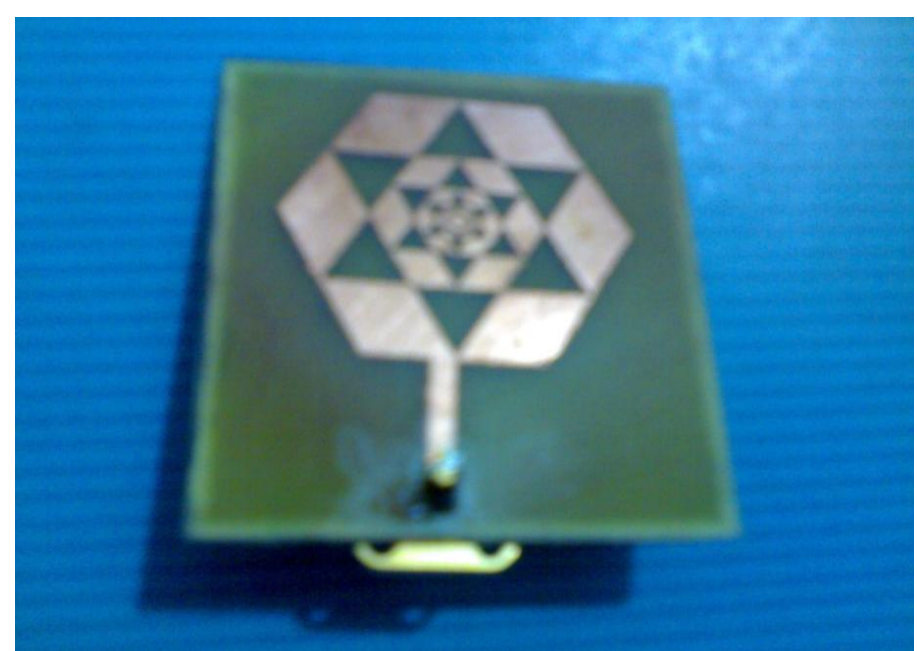

(a) Top view of fabricated fractal antenna 


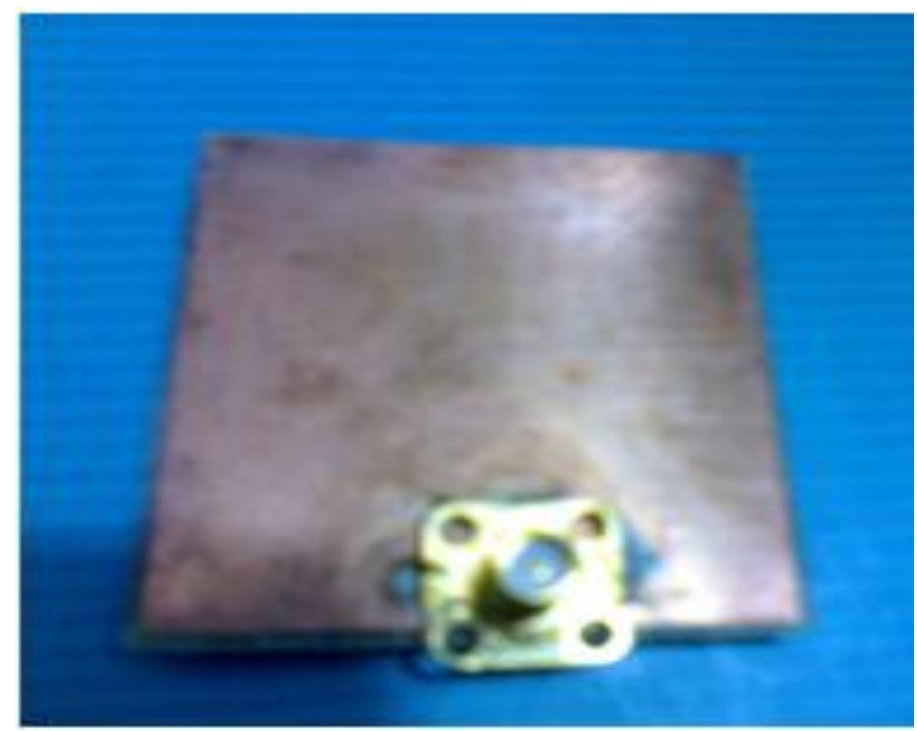

(b) Bottom view of fabricated fractal antenna

Fig 9 Fabricated fractal antenna

\section{CONCLUSION}

Size reduction of the antenna is achieved. The characteristics of proposed antenna are studied. Proposed antenna improved the fractional bandwidth upto $47.97 \%$. The proposed antenna has been designed on glass epoxy substrate to give a maximum radiation efficiency of about $94.98 \%$, gain of about $2.88 \mathrm{dBi}$ and directivity of $3.12 \mathrm{dBi}$.The proposed antenna is suitable for WLAN, WiMAX and Bluetooth applications.

\section{REFERENCES}

[1]. C.A. Balanis, Antenna Theory Analysis and Design, 3rd Edn, (A John Wiley \& Sons, Inc. Publication, 2005).

[2]. Girish Kumar, K. P. Ray, Broadband Microstrip Antennas, (Artech House Inc., 2003), pp. 1-21.

[3]. S. Maci and G. BifJi Gentili, Dual Frequency Patch Antennas, IEEE Transactions on Antennas and propagation, Vol.39, No.6, pp. 13-20, Dec. 1997.

[4]. K.J.Vinoy, Jose K. Abraham, and Vijay K. Varadan, On the Relation- ship between Fractal Dimension and the Performance of Multi-Resonant Dipole Antennas Using Koch Curves, IEEE Transactions on Antennas and propagation, Vol. 52, No.6, pp. 1626-1627, June 2004.

[5]. Douglas H. Werner, Randy L. Haup, and Pingjuan L. Werner, Fractal Antenna Engineering: The Theory and Design of Fractal Antenna Arrays, IEEE Transactions on Antennas and propagation, Vol.41, No.5, pp. 37-58, Oct. 1999.

[6]. Anessh Kumar, A Modified Fractal Antenna for Multiband Applications, IEEE International Conference on Communication Control and Computing Technologies, pp. 47-51, Oct. 2010.

[7]. Carmen Borja and Jordi Romeu, On the Behavior of Koch Island Fractal Boundary Microstrip Patch Antenna, IEEE transactions on Antennas and propagation, Vol.51, No.6, pp.1281-1291, June 2003.
[8]. Ilk Won Kim and TacHoon Yoo, The Koch Island Fractal Microstrip Patch Antenna, International Symposium on Antenna and Propagation Society, Vol.2, pp. 736-739, 2001.

[9]. Carles Puente Baliarda, Jordi Romeu and Angel Cardama, The Koch Monopole: A Small Fractal Antenna, IEEE Transactions on Antennas and Propagation, Vol. 48, No. 11, pp. 1773-1781, Nov. 2000.

[10]. Carmen Borja and Jordi Romeu, Fracton Vibration Modes in the Sierpinski Microstrip Patch Antenna, International Symposium on Antenna and Propagation Society, Vol.3, pp. 612-615, 2001.

[11]. Ananth Sundaram, Madhurima Maddela and Ramesh Ramadoss, Koch Fractal Folded Slot Antenna Characteristics, IEEE Transactions on Antennas and Wireless Propagation Letters, Vol.6, pp. 219-222, 2007. 